NBER WORKING PAPER SERIES

\title{
SUBJECTIVE OUTCOMES IN ECONOMICS
}

\author{
Daniel S. Hamermesh \\ Working Paper 10361 \\ http://www.nber.org/papers/w10361 \\ NATIONAL BUREAU OF ECONOMIC RESEARCH \\ 1050 Massachusetts Avenue \\ Cambridge, MA 02138 \\ March 2004
}

This was the Association Lecture delivered at the Southern Economic Association meetings, San Antonio, Texas, November 22, 2003. I thank Stephen Haider and Stephen Trejo for helpful comments. The views expressed herein are those of the author and not necessarily those of the National Bureau of Economic Research.

(C2004 by Daniel S. Hamermesh. All rights reserved. Short sections of text, not to exceed two paragraphs, may be quoted without explicit permission provided that full credit, including $\odot$ notice, is given to the source. 
Subjective Outcomes in Economics

Daniel S. Hamermesh

NBER Working Paper No. 10361

March 2004

JEL No. J000, I000

\section{ABSTRACT}

This study examines the various uses of subjective outcomes as a focus of interest for economists. It outlines the possible channels by which economists can usefully add to what are already massive literatures on such outcomes in the other social sciences. Generally we contribute little if we merely engage in fancier empirical work and still less if we describe subjective outcomes by other subjective outcomes. Our biggest contributions can be in adducing economic theories that allow a better understanding of objective behavior using subjective outcomes, or of the determinants of subjective outcomes; or in understanding subjective outcomes, such as expectations, that underlie objective economic behavior.

Daniel S. Hamermesh

Department of Economics University of Texas Austin, TX 78712-1173

hamermes@eco.utexas.edu 


\section{Introduction}

There has been an upsurge in the use and analysis in economics of subjective outcomes. A long survey paper (Frey and Stutzer 2002) discussed some of the literature, but even that was restricted to only one part of the interest in this type of outcome. A relevant question is why economists are looking at these expressions of behavior now. I think it is partly due to the fact that we are seeking things to do with the large amounts of data that we have suddenly discovered - the Mt. Everest phenomenon, if it's there, we must climb it. Partly too, it may be that we believe that our skills enable us to do better jobs of analyzing outcomes that have previously been in the sole purview of other social scientists.

In the mid-1970s I did some research on a subjective outcome- job satisfaction. The comment from the editor of a journal to which I submitted the paper was "This is not economics." Was the editor correct, and would he still be correct today? There is a lot of work being done on these topics, but what kind of work should we be doing? Here I go through a variety of examples of my own and others' research in trying to distinguish between the kinds of topics where we have something to offer and others where we do not. I neglect many examples with which I am not familiar that may be at least as good as those that I present. This brief discussion indicates that there is a disjuncture between what we economists are doing in these areas and what we should be doing.

This discussion raises a larger question, which I am not going to answer: "Is there anything beyond the scope of economics?" I have some bona fides in asking this question, having written papers on such bizarre topics as suicide, beauty and sleep that some people argue are not subjects that we should be working on. If those topics are off limits for us, discussing the economics of subjective outcomes is even further away from what we should be considering. Some of it is; but I will try to demonstrate that some of these things are very 
much within our purview, and that we should be thinking about them. While I cover a fair number of topics, there are other subjective measures (e.g., preferences toward risk, rates of time preference) that I do not discuss but that have been studied by economists and used in empirical analyses of economic outcomes.

\section{Life Satisfaction}

The first research area that I deal with is life satisfaction: How happy one is with one's life. Economists' work on this topic comprises, if not the majority of our research on subjective outcomes, at least surely a plurality. The general idea here is to obtain data on how satisfied the subjects are, based on their subjective responses, and to look at the effects of economic variables on their satisfaction. The typical economic variable is income. The general research question is, "How happy does your income make you?" Many of the people who work in this area try to equate this happiness measure with utility (with Lévy- Garboua and Montmarquette 1997, being the best example so far). On the surface this is very appealing. Utility is one of the two foundation ideas that we deal with in our intro micro classes, and it is a topic we should be able to say something about. How happy are people over time within a country? How happy are people across countries? What are the effects of various demographic correlates on differences in happiness?

I find most of the analysis by economists on this issue to be rather silly. The first difficult issue is the scaling problem - the problem of converting what must be some continuous ordinal measure into a measure described by a few categories. How people scale it in their own minds is a question that we economists have barely begun to think about, although cognitive psychologists have paid this issue substantial attention.

The larger problem, however, is not the scaling problem. I am willing to admit that we might not be able to solve the scaling problem; but at least we can wave our hands and 
say that somehow there is an underlying ordinal index of people's behavior that could be captured if we were able to spy on them sufficiently carefully. But there is another problem here: There is no apparent link of these subjective responses to any underlying measure of utility, at least measures that maintain the properties that we desire for utility functions. On a theoretical basis, Homans (1961) pointed out that there is no reason to believe that long-run improvements in objective circumstances will generate long-run increases in subjective responses. While we generally believe that utility rises with additional inputs of goods and the time to consume them, many psychologists believe that satisfaction adjusts to expectations about living standards. If we believe that utility equals expressed satisfaction, there is little justification for any policy designed to raise living standards.

On the empirical side, there are books and articles surveying hundreds of empirical studies of life satisfaction by psychologists (e.g., the survey by Diener and Biswas-Diener 2002). If you examine this literature, you find that every specification that economists have used has also been included in at least several psychological studies. For example, I discussed a paper at the 2002 AEA meetings (Gardner and Oswald 2001), which received immense amounts of press, in which the focus was on lottery winners. If I won the Texas Lotto, I would be very happy for a while. But after I was used to the lottery win, I would think, "The lottery's my due, I deserve to have won it." My satisfaction would revert to its mean. This is exactly what was observed in this study. It is also exactly what was shown in two very similar studies of lottery winners done by psychologists in the 1970's.

Our ability to push buttons in STATA, SAS, TSP, or whatever, is not unique: Psychologists and sociologists are perfectly capable of doing that. Our strength, I would argue, and the thing that should underlie whether we do anything in this area, is the extent to which we can bring economic theory to bear on the specifications that we try to formulate. 
On this topic in particular I have seen nothing where any economic theory has been brought to bear. Thus, in terms of a hierarchy that I will summarize at the end of this article, it is clear that economists' work on this topic has not progressed very far. ${ }^{1}$ Now perhaps somebody will generate more ideas that use economics here; but simply running fancy regressions on this subject is not new (except to economists). Although I would like to see more people working in this area, thus far we have not done much to justify our incursions.

\section{Job Satisfaction}

I have published two papers on job satisfaction, one each quarter century (Hamermesh 1977, 2001). To show that I am not completely self-congratulatory, I rather doubt that we have offered much in this area either. We have only one notion here that other fields do not have, and that is the idea of equilibrium. If people choose an occupation based on the returns to working in it, then a permanent shock to those returns will in the long run have no effect on the average satisfaction of workers in the occupation. A little testing of that idea - putting it into the context of wage determination, which psychologists do not seem to have done-might have some small value. There is no real basis in economic theory; there is just the notion of equilibrium, of adjustment to what one expected upon making one's investments in human capital — end of story.

To demonstrate that there is some evidence of equilibration in people's stating subjectively their job satisfaction I looked at information for the United States (Hamermesh 2001) that links changes in job satisfaction across earnings quartiles to interquartile changes in income inequality. This is essentially a double-difference study, estimated using data from various National Longitudinal Surveys for the United States.

Interquartile differences in job satisfaction and earnings inequality grew in tandem over the period 1978-88 - a time when the very rapid growth in earnings inequality began in 
the U.S. When one looks at changes over the longer period, 1978-96, the picture looks entirely different. Workers in the top earnings quartile no longer exhibited higher job satisfaction than those in the second and third earnings quartiles. They appear to have become somewhat used to their increased relative earnings - to the increased returns to their skills.

A similar analysis in that study used data from the German Socioeconomic Panel. In Germany there was almost no change in interquartile earnings inequality over 1984-94; and interquartile differences in the fractions of people responding that they were highly, somewhat or fairly satisfied during this period compared to the fraction stating that they were dissatisfied were also quite small. Between 1994 and 1996, however, earnings inequality, especially the advantage of the top earners over other workers, rose rapidly. At the same time, the difference in average satisfaction of top earners over others became much greater. The stimulus of a rapid rise in earnings generated an immediate response of a sharp rise in job satisfaction.

One might argue that, by using double differences, this approach also circumvents the problem of scaling in categorical subjective variables, so that it might handle both of the problems I alluded to in discussing life satisfaction. I am dubious about that; and surely without detailed work on cognitive responses to these questions (a task for which economists are ill-prepared), one cannot make any such claims. Perhaps the best to be said about this literature is that we economists have made a very small contribution to a large socialscientific literature.

\section{Subjective Health Outcomes}

The next area is one in which I have not worked, although many people have. The standard measure of health status asks survey respondents to rate their health on a numerical 
scale, typically denoting excellent, very good, good, fair or poor. Many labor economists, including me, have used this measure as a control variable on the right-hand side of wage and other equations. Why do we use this subjective outcome? Very simply, we usually cannot take blood samples, measure heart rates or count cholesterol when we conduct the large surveys that provide most of our data. Instead, we ask the respondents how healthy they are. Is there any economic content in explaining these subjective health outcomes? There is a large literature on health production functions, and we can measure the effects of inputs on this subjective outcome. There is an important economic question here: Does spending on health improve health? While we can measure health objectively through morbidity and mortality measures, in large micro data sets of living people we typically do not have those measures. Since the evidence (Bound 1991) indicates that this subjective measure is fairly highly correlated with some objective measures of health status, as a cost-effective first-pass at the issue it has some value. We can thus use it as a way around our inability to get objective measures of health outcomes. Marrying it to what we believe might be objective determinants of health status through the notion of a production function is something we should approve of.

\section{Measuring Expectations}

Expectations are inherently subjective - they deal with events on which objective measures cannot as yet be provided. A number of purely subjective expectations are central to testing basic theories of economics. When we write down the lifetime maximization of the consumer, for example, we derive paths of consumption, labor supply, wealth and other outcomes from the dynamic optimization problem defined over a horizon, T. How long is T? This is rather important. As another example, what is the subjective discount rate in this maximand, something that surely differs across people? 
As an illustration I deal here with expectations about the horizon, $\mathrm{T}$, and about expectations of the probability of survival through various future years. The idea in this example was to elicit from people information about their expectations of longevity and to append it to a representative dataset to examine the role of expectations in the consumer's lifetime maximization problem. To do this I undertook two mail surveys of randomly selected adult males, economists and others (Hamermesh 1985), obtaining information on expected length of life and various personal characteristics. The surveys included questions about the length of life of the respondent's parents and grandparents.

To infer the impact of the objective measures on expected longevity I estimated the regressions presented in Table 1. (Other variables in the equations tested for the rationality of forecasts by using information from life tables and are unimportant here.) The crucial variables are those for old and young grandparents and parents (whether one's forebears died naturally before age 60 or lived beyond age 79), as their estimated impacts on subjective longevity in these samples can be used to create forecasts of longevity in some of the large random samples that empirical economists use. The results are heartening, in the sense that the forecasts of members of both samples are sensitive to the life experiences of their parents and grandparents. Indeed, they are too sensitive - they overstate what the epidemiological evidence suggests is the objective relationship (Hamermesh and Hamermesh 1983), but that excess enhances their value in creating forecasts of expectations in large samples. ${ }^{2}$

Using the 1975 wave of the Retirement History Survey, and the Terman sample of high-IQ Californians and their families, I linked these results to information on the respondents' parents' ages at death to create variables proxying the respondents' horizons (Hamermesh 1984). These were then used to examine whether, other things, including financial wealth, equal, these older Americans' consumption of goods and leisure differed as 
their imputed horizons differed. The results, contained for the RHS sample in Table 2, suggest that the length of the horizon does affect these important life-cycle outcomes. Consumption spending in particular is reduced among otherwise identical people if their horizons are longer. The effects of increases in the subjective horizon on market work are relatively much smaller and less significant statistically, but they are in the expected direction.

The samples from which subjective expectations were obtained were quite small, and the respondents whose behavior was examined were not those whose expectations about longevity were elicited. More recently, the Health and Retirement Survey has obtained information from a panel of older Americans on their expectations of longevity and their spending and labor-force behavior. Within this one data set researchers (e.g., Gan, Hurd and McFadden, 1998; Haider and Stephens 2004) have begun to examine the interactions between the subjective horizon and the crucial variables that result from lifetime utility maximization. This combination avoids the loss of information on idiosyncratic behavior that plagued my now-ancient research.

This stuff is great fun - and it speaks to some of the central issues in both microeconomics and macroeconomics. By itself, however, the work on expectations contains no economic analysis - it merely estimates regressions on a subjective outcome using a set of variables that I believed, with no theoretical justification, might affect expectations, and I then appended the results to standard econometric models. The justification for an economist undertaking this kind of analysis - this atheoretical empirical discussion of a subjective outcome - is that the results are important inputs to our basic research and are not likely to be considered (and were not discussed) by other social scientists. 


\section{Time Stress}

Some issues are inherently subjective and describe outcomes that would seem to be entirely outside the purview of economists. The crucial word here is "seem" - topics like fertility, discrimination, sumo wrestling, and many others may at one time have seemed outside our area of expertise; but if by using economic theory we can advance knowledge of these subjects, they become economic topics. Jacob Viner once remarked that economics is what economists do. I would modify that to note that economics is what economists do if economists use economic theory.

One area that I believe fits this description is the analysis of time stress, on which I have recently been working (Hamermesh and Lee 2003). The issue here is purely subjective — what determines how rushed people feel? Previous analysis, by social psychologists and sociologists, has linked these feelings to the presence of children and to time allocation at home and in the workplace. Economic theory, particularly the theory of household production (Becker 1965), allows us to recognize that time use is affected by financial resources, and thus that the extent to which a time constraint binds is in the end an increasing function of the opportunity cost of the time of an individual and other members of his/her household. The explicit prediction, which is far from intuitively obvious (and even, from many discussions, clearly unthinkable by intelligent laypeople or many other social scientists) is that otherwise identical people whose incomes are greater will feel more rushed for time. The same prediction holds even more strongly if one does not hold constant for differences in time use.

We examined this hypothesis for a number of countries (Hamermesh and Lee 2003) by relating subjective responses about how stressed respondents in large micro data sets are for time. The determinants in each sample were the individual's hours of market work, hours 
of non-market work, earnings (and thus full income, since hours of market work are held constant) and spouse's earnings and time allocation. Various demographic and locational controls were included for each of the data sets.

Otherwise identical men and women in couples with higher incomes are more stressed for time - feel more rushed — holding constant their use of time. The effects are not insubstantial—one-standard-deviation increases in household pay raise the percentages of workers who state that they are stressed by three to fifteen percentage points (over sample means ranging from 33 to 45 percentage points). In North America and Canada the effects of interquantile increases in earnings in increasing time stress begin to approach those of interquartile increases in hours of market work. Someone might claim that common traits generate positively correlated errors in both income and expressed time stress (although as an economist I would rather assume that differences in traits are uncorrelated with income). Even that essentially non-economic objection would seem vitiated by the additional finding (for Germany) that non-working (in the market) women with high-earning husbands are more stressed for time than their otherwise identical compatriots whose husbands earn less. The results demonstrate that people with a higher value of time are more stressed for time, not only because they may work more, but because the command that they possess over goods makes them busy spending their incomes.

Here is an example where simple economic theory generates a prediction that is novel and utterly unattainable without using theory. While the outcome is subjective and not inherently interesting to economists, it is directly linked to areas - time use and consumption - that we study extensively. While we do not study how people feel about issues in these areas, other social scientists do; and we have something useful and unique to say about these feelings. 


\section{Some Recent Negatives and Positives}

What is disturbing is that, in addition to our welcome forays into using economic theory to describe the determinants of subjective outcomes, and to analyzing the formation of the subjective determinants of economic outcomes, we are also increasingly making forays into studying how subjective outcomes are affected by subjective measures. Thus, for examples: 1) Coleman and DeLeire (2003) have analyzed how youths' expectations about their incomes at age 30 are affected by the extent to which the youth "felt in control" at age 13; 2) Boex (2000) examined how students' instructional ratings of their professors are affected by the same students' perceptions of the professors' lecturing ability; 3) McGarry (2002) used using respondents' self-assessed health status to describe retirement expectations.

There is nothing wrong with this if we are interested in how expectations affect expectations per se, although I see no economic content in that issue. If, however, we are using a subjective measure to proxy an objective determinant of a subjective outcome, the difficulty is readily apparent from the following simple set-up. We are interested in the determinants of subjective outcome $\mathrm{S}^{*}$ by objective determinant $\mathrm{B}$ and controls $\mathrm{X}$, and we have information on a large set of respondents indexed i. We wish to estimate:

$\mathrm{S}_{\mathrm{i}}^{*}=\alpha \mathrm{X}_{\mathrm{i}}+\beta \mathrm{B}_{\mathrm{i}}+\varepsilon_{\mathrm{i}}$,

where $\varepsilon_{\mathrm{i}}$ is an error term. The difficulty is that we do not observe $\mathrm{B}$, instead having information only on some subjective proxy for it, BS. Now BS may be a fairly good predictor of $\mathrm{B}$, as in the case of self-assessed health. But like any subjective outcome it will be shaded by some person-specific effect, $\theta_{\mathrm{i}}$, reflecting person i's general optimism or pessimism. A person-specific effect $\eta_{\mathrm{i}}$ also shades the subjective response $\mathrm{S}^{*}$ and is likely to be highly positively correlated with $\theta_{\mathrm{i}}$. We thus have as observables: 
$\mathrm{BS}_{\mathrm{i}}=\mathrm{B}_{\mathrm{i}}+\theta_{\mathrm{i}}$

and:

$\mathrm{S}_{\mathrm{i}}=\mathrm{S}_{\mathrm{i}}^{*}+\eta_{\mathrm{i}}$

When we estimate using the observables S and BS:

$\mathrm{S}_{\mathrm{i}}=\alpha \mathrm{X}_{\mathrm{i}}+\beta\left[\mathrm{BS}_{\mathrm{i}}+\theta_{\mathrm{i}}\right]+\varepsilon_{\mathrm{i}}$

we are really estimating:

$\left[\mathrm{S}_{\mathrm{i}}^{*}+\eta_{\mathrm{i}}\right]=\alpha \mathrm{X}_{\mathrm{i}}+\beta\left[\mathrm{B}_{\mathrm{i}}+\theta_{\mathrm{i}}\right]+\varepsilon_{\mathrm{i}}$.

The same difficulty arises if we wish to describe some objective outcome by a subjective measure and proxy the dependent variable by some subjective measure. The extent of the difficulty in both cases depends on the relative contributions of $\sigma_{\theta}$ to $\sigma_{\mathrm{BS}}$ and $\sigma_{\eta}$ to $\sigma_{\mathrm{S}}$, and on how strongly positive is the correlation between $\theta$ and $\eta$. The degree of bias thus varies from case to case. It is hard to believe, however, given the $\mathrm{R}^{2}$ that we typically produce in micro data, that the positive correlations between the observed variables of interest that are induced by this problem are not large in nearly all cases. In short, even if we rationalize equations like (1) as having a basis in objective behavior, the need to use subjective proxies usually obviates any hope of correctly estimating a behavioral relationship. ${ }^{3}$

A number of other inherently subjective expectational and other outcomes should be of interest to economists, as the extent of rationality in their revision is important. Thus, for examples, Charles (2002) examined how depression among older Americans is affected by their retirement status, cleverly using kinks in retirement incentives under the American OASI scheme to circumvent problems of simultaneity. Lochner (2003) used the NLSY97 to examine whether arrest led young people to alter their perceptions of the criminal justice system. 
One could at least as well analyze the impacts of these and other subjective measures on economic outcomes. Thus it would be interesting to know how changing expectations about arrest and punishment probabilities affect individuals' propensities to commit crimes. In another area, it would be interesting to learn how individuals' preferences for neighbors of the same income (or race) as themselves affect patterns of residential location. ${ }^{4}$

\section{A Hierarchy for Research}

The availability of interesting questions; the immense amount of data; and, despite the burgeoning interest among economists, the relative paucity of economic research make the analysis and use of subjective outcomes a fertile field for us, and one that is likely to be heavily ploughed by economists in the next decade. We need to be careful, however, to ensure that we use our skills and do not merely replicate what other social scientists have accomplished; still worse, we should not abandon our comparative advantage — our frameworks for analyzing maximizing behavior by individuals and how that behavior affects individual and group outcomes.

We should keep in mind the following hierarchy that moves from less to more desirable approaches to research using subjective measures:

1. Atheoretical statistical models examining subjective outcomes and explaining them by their subjective determinants. We economists should view this approach as a no-no-we can learn nothing about objective behavior from this approach, and in most cases cannot even use it to describe the determinants of subjective outcomes.

2. Atheoretical statistical models examining the objective determinants of subjective outcomes that are not relevant inputs into describing economic behavior. These kinds of studies that have proliferated in other disciplines. They are interesting to the intelligent 
layperson and to other social scientists, but as economists we have little novel to add to the discussion.

3. Atheoretical statistical models examining the objective determinants of subjective outcomes that are important inputs into describing economic behavior. While other social scientists might have studied these, in most cases we know better what subjective measures are the most important variables in our models of objective economic behavior.

4. Theoretically based statistical models of important, albeit non-economic outcomes. There are no doubt many other areas besides time stress where we can analogize a subjective outcome of general interest to a concept in one of our models and derive how individual agents' maximizing behavior affects the outcome.

5. Theoretically based statistical models of the determinants of economically relevant subjective outcomes. I have seen nothing of this type yet, but I view it as the summit that we should be trying to reach.

Research on the determinants of subjective outcomes and work using those outcomes to describe objective behavior are booming areas among economists. As the boom continues, we need to be careful to base the research on our comparative advantage—our coherent models of underlying behavior-lest we either duplicate what other social scientists have already done many times over or, worse still, generate results that have no absolutely economic meaning. 


\section{REFERENCES}

Becker, Gary. 1965. A theory of the allocation of time. Economic Journal 75: 492-517.

Boex, L.F. Jameson. 2000. Attributes of effective economics instructors: An analysis of student evaluations. Journal of Economic Education 31: 211-227.

Bound, John. 1991. Self-reported versus objective measures of health in retirement models. Journal of Human Resources 26: 106-138.

Charles, Kerwin K. 2002. Is retirement depressing? Labor force inactivity and psychological well-being in later life. NBER Working Paper No. 9033.

Coleman, Margo and Thomas DeLeire. 2003. An economic model of locus of control and the human capital investment process. Journal of Human Resources 38: 701-721.

Diener, Edward, and Robert Biswas-Diener. 2002. Will money increase subjective wellbeing? Social Indicators Research 57: 119-69.

Di Tella, Rafael, Robert MacCulloch, and Andrew Oswald. 2001. Preferences over inflation and unemployment: Evidence from surveys of happiness. American Economic Review 81: 335-41.

Frey, Bruno, and Alois Stutzer. 2002. What can economists learn from happiness research? Journal of Economic Literature 40: 402-435.

Gan, Li, Michael Hurd, and Daniel McFadden. 1998. Subjective Probabilities and Saving Behavior. In Inquiries in the economics of aging, edited by David Wise. Chicago: University of Chicago Press, pp. 259-305.

Gardner, Jonathan and Andrew Oswald. 2001. Does money buy happiness? A longitudinal study using data on windfalls. Unpublished paper, University of Warwick, March. 
Haider, Steven, and Melvin Stephens. 2004. Is there a retirement-consumption puzzle? Evidence using subjective retirement expectations. Unpublished paper, Michigan State University, January.

Hamermesh, Daniel. 1977. Economic aspects of job satisfaction. In Essays in labor market and population analysis, edited by Orley Ashenfelter and Wallace Oates. New York: J. Wiley \& Sons, pp. 53-72. 1984. Life-cycle effects on consumption and retirement. Journal of Labor Economics, 2: 353-370. 1985. Expectations, life expectancy and economic behavior. Quarterly Journal of Economics 100: 389-408. -. 2001. The changing distribution of job satisfaction. Journal of Human Resources 36: 1-30. and Frances Hamermesh. 1983. Does perception of life expectancy reflect health knowledge? American Journal of Public Health 73: 911-914. , and Jungmin Lee. 2003. Stressed out on four continents: Time crunch or yuppie kvetch? NBER Working Paper No. 10186.

Homans, George. 1961. Social behavior: its elementary forms. New York: Harcourt Brace. Lévy-Garboua, Louis, and Claude Monmarquette. 1997. Reported job satisfaction: What does it mean? CIRANO Working Paper 97s-09, University of Montreal.

Lochner, Lance. 2003. Individual perceptions of the criminal justice system. NBER Working Paper No. 9474.

McGarry, Kathleen. 2002. Health and retirement: Do changes in health affect retirement expectations? NBER Working Paper No. 9317. 
Winkelmann, Rainer. Subjektive Daten in der empirischen Wirtschaftsforschung: Probleme und Perspektiven. 2002. Unpublished paper, Institute for Empirical Economic Research, University of Zürich, June. 


\section{FOOTNOTES}

${ }^{1}$ An example of useful work on this topic that, although it lacks an economic-theoretic basis, at least uses subjective outcomes to analyze questions that only economists would consider, is Di Tella, MacCulloch and Oswald (2001).

${ }^{2}$ Unlike these, the estimated impacts of smoking on subjective longevity accord well with objective evidence, a finding that has been used repeatedly by other economists to defend tobacco companies against lawsuits by ex-smokers or their heirs.

${ }^{3}$ Winkelmann (2002) discusses other econometric issues in analyzing subjective outcomes.

${ }^{4}$ I am indebted to Stephen Ross for suggesting this example. 
Table 1. Determinants of Subjective Life Expectancy

Economists SMSA sample

Old grandparents:

$\begin{array}{lrr}1 & 0.65 & 0.28 \\ & (0.78) & (0.28) \\ & 2.07 & 1.05 \\ 3 \text { or } 4 & (2.34) & (0.89) \\ & 2.62 & 1.44 \\ & (2.54) & (0.97)\end{array}$

Young grandparents:

$\begin{array}{lrr}1 & -2.10 & -0.70 \\ & (-2.88) & (-0.68) \\ & & \\ & -2.43 & -0.13 \\ \text { or } 4 & (-2.16) & (-0.07) \\ & & \\ & -5.39 & -4.87 \\ & (-1.64) & (-1.20)\end{array}$

Old parents:

$\begin{array}{lrr}1 & 3.01 & 1.27 \\ & (2.92) & (0.95) \\ & 5.94 & 4.14 \\ & (4.26) & (1.87) \\ \text { Young parent(s) } & & \\ \text { 1 or 2 } & -1.78 & -2.64 \\ & (-2.18) & (-2.09) \\ \text { Smoke } & -1.92 & -3.47 \\ & (-2.00) & (-2.98) \\ \text { Exercise } & 0.08 & 0.93 \\ & (0.12) & (1.05) \\ \text { Illness } & -3.96 & -5.65 \\ & (-3.94) & (-3.93)\end{array}$

${ }^{\mathrm{a}}$ Reproduced from (Hamermesh 1985, p. 401). t-statistics in parentheses here and in Table 2 . 
Table 2. Parameter Estimates on Leisure and Goods Consumption, RHS, 1975 $(\mathrm{N}=1,422)^{\mathrm{a}}$

Leisure Goods $(\$ 000)$

$\begin{array}{lcc}\text { Social security } & -.0012 & .011 \\ \text { wealth } & (-1.62) & (2.48) \\ & & .029 \\ \text { Pension wealth } & .0045 & (9.23) \\ & (8.43) & \\ & & .016 \\ \text { Other wealth } & -.00037 & (12.37 \\ & (-1.83) & \\ & & .142 \\ \text { After-tax earnings } & --------- & (13.02) \\ & & -.073 \\ \text { T } & & (-1.30)\end{array}$

Weighted $\mathrm{R}^{2}$

${ }^{\mathrm{a}}$ Reproduced from (Hamermesh 1984, p. 365). A wide array of demographic and locational controls is also included. The equations are estimated as a system. 